\title{
2015-2019 yılları arasında çocuk endokrinoloji servisine yatırılmış diyabetes mellitus tanılı olguların yatış durumlarının değerlendirilmesi
}

\section{Evaluation of patients diagnosed with diabetes mellitus hospitalized in pediatric endocrinology service between 2015-2019}

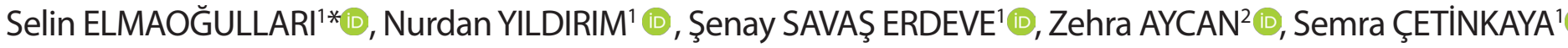

'Sağlık Bilimleri Üniversitesi, Dr. Sami Ulus Kadın Doğum Çocuk Sağlığı ve Hastalıkları Eğitim ve Araştırma Hastanesi, Çocuk Endokrinoloji Kliniği, Ankara / TÜRKIYE

${ }^{2}$ Ankara Üniversitesi Tıp Fakültesi, Ergen Sağlığı Bilim Dalı, Ankara /TÜRKiYE

\section{Öz}

Amaç: Bu çalışmada 4 yıl süresince çocuk endokrinoloji servisinde yatıılarak izlenmiş diyabetes mellitus (DM) tanıı hastaların yatış nedenlerinin belirlenmesi ve diyabet tiplerininin yıllara göre dağılımının incelenmesi planlandı.

Gereç ve Yöntemler: Ocak 2015-Ocak 2019 tarihleri arasında çocuk endokrinoloji servisine yatışı yapılmış DM tanılı hastaların dosyaları geriye dönük olarak incelendi. Hastalar diyabet tiplerine ve yeni/eski tanı olmalarına göre gruplandırıldıktan sonra, yeni tanı alan olguların başvurudaki metabolik durumları (hiperglisemi/ketoz/ketoasidoz) ve eski tanılı hastaların yeniden yatış nedenleri kaydedildi.Aynı hastanın tekrarlayan hastane yatışlarının her biri ayrı yatış olarak değerlendirildi.

Bulgular: Diyabetes Mellitus tanılı hastalara ait toplamda 787 yatış belirlendi. Yatışların \%90,6'sı Tip 1 diyabet (T1DM) ve \%4,2'si Tip 2 diyabet (T2DM) tanılı hastalara aitti. Yeni tanı T1DM sayısının son 2 yılda arttığı ancak ketoasidozla başvurma oranının giderek düştüğü belirlendi $(p=0,03)$. Takipli hastaların yatış nedenleri incelendiğinde yatışların \%72,4'ünün poliklinik kontrolleri sırasında kan şekeri değerlerinde düzensizlik ve/veya hasta uyumsuzluğu görülmesi nedeniyle regülasyon ve diyabet eğitimi tekrarı amaçlı, \%6,3'ünün ketoz/ketoasidoz gelişmesi nedeniyle yapıldığı gözlendi.

Sonuçlar: Çocuklarda diyabet sıklığının artmasıyla birlikte diyabet nedeniyle hastaneye yatış sıklığı da artmaktadır. Ailelerde artan diyabet farkındalığı ile ilişkili olarakyeni tanıT1DM'deketoasidozla başvuru oranı azalmıştır. Bu konudaki okul çalışmaları ve kamu spotlarına devam edilmeli ayrıca T2DM ve obezite konusunda bilinçliliğin arttırılması hedeflenmelidir. Takipli hastalarda tedaviye uyum düzenli olarak değerlendirilmeli ve diyabet eğitiminin sürekliliği sağlanmalıdır.

Anahtar Kelimeler: Çocuklar; tip 1 diyabetes mellitus; tip 2 diyabetes mellitus.

Sorumlu Yazar*: Selin ELMAOĞULLARI, Sağlık Bilimleri Üniversitesi, Dr. Sami Ulus Kadın Doğum Çocuk Sağlığı ve Hastalıkları Eğitim ve Araştırma Hastanesi, Çocuk Endokrinoloji Kliniği, Ankara / TÜRKIYE

E-mail: selmaogullari@hotmail.com

ORCID: 0000-0003-4879-7859

Gönderim: 30.10.2020 kabul: 08.07.2021

Doi: 10.18663/tjcl.833021 


\section{ABSTRACT}

Aim: We planned to determine the reasons for the hospitalization of patients with diabetes mellitus (DM) in the pediatric endocrinology service and examine the distribution of diabetes types by years.

Material and method: Patients diagnosed with DM hospitalizedinpediatric endocrinology service between January 2015 and January 2019 were retrospectively reviewed.Patients were grouped according to their diabetes types and diagnosis time as new or old diagnoses.The metabolic status of the newly diagnosed cases (hyperglycemia / ketosis / ketoacidosis) andreasons for rehospitalization of formerly diagnosed patients were recorded. Each of the repeated hospitalizations of the same patient was evaluated as a separate hospitalization.

Results: A total of 787 admissions for patients with DM were identified. $90.6 \%$ of hospitalizations belonged to patients with Type 1 DM (T1DM) and 4.2\% Type 2 DM (T2DM). The number of newly diagnosed T1DM patients has increased in the last 2 years. However, it was determined that the rate of referrals with ketoacidosis was gradually decreasing $(p=0.03) .72 .4 \%$ of the patients on diabetes follow-up were hospitalized for regulation of treatment and repeating of diabetes education because of the irregularity in blood glucose values and/or patient incompatibility during outpatient clinic controls and $6.3 \%$ were hospitalized due to the development of ketosis /ketoacidosis.

Conclusion: As the prevalence of diabetes in children increases, the frequency of hospitalizations due to diabetes also increases. In relation to the increased awareness of diabetes in families, the rate of presentation with ketoacidosis has decreased in newly diagnosed T1DM. School studies and spots on this subject should continue to increase awareness about T2DM and obesity. Compliance with treatment should be evaluated regularly in followed-up patients and continuity of diabetes education should be ensured.

Keywords: Children; type 1 diabetes mellitus; type 2 diabetes mellitus.

\section{Giriş}

Diyabetes mellitus (DM) dünya çapında önemli bir halk sağlığı sorunudur. Tip 1 DM (T1DM) pankreas beta hücresinin otoimmün yıkımına bağlı azalan insulin salgısı sonucu gelişen hiperglisemi ile karakterizedir ve çocukluk çağında DM'nin en sık (\%90) nedenidir. Tip 2 DM (T2DM) ise insulin direnci ve beta hücre fonksiyonundaki göreceli azalmaya bağlı insulin aktivitesindeki yetersizlikle karakterizedir [1]. Çocuk ve ergenlerde T1DM ve T2DM görülme sıklığı dünyanın pek çok yerinde son 30 yılda artış göstermiştir. Dünya çapında her yıl 15 yaş altı 96000 çocuğun T1DM geliştirdiği bilinmektedir [2]. Çocuk ve ergenlerde T2DM insidansı ise ülke ve etnik gruplara göre değişmekle birlikte 1-51/1000 olarak bildirilmiştir [3].

Yeni DM tanısı alan çocuk ve ergenlerde, tanı anında ketoz/ketoasidoz olmasa dahi, T1DM' de insülin dozlarının belirlenmesi ve diyabet eğitiminin verilmesi için;T2DM ve diğer diyabet tiplerinde ise kan glukoz profilinin görülmesi, tedavi rejiminin belirlenmesi ve komorbidite taraması için, hemen daima hastaneye yatış gereklidir. Tanı sonrası dönemde de DM'li hastaların hastaneye yatış oranı artmışıı. Genel populasyonla karşılaştııılığında, T1DM'li çocuklarındiyabet komplikasyonları veya diyabet dışı nedenlerle hospitalize edilme olasılığı 4-8 kat fazla, hastanede kalma süreleri iki kat uzundur [4].

Bu çalışmada 4 yıl süresince çocuk endokrinoloji servisinde yatırılarak izlenmiş DM tanılı hastaların yatış nedenlerinin, diyabet tiplerininin ve yıllara göre dağılımının incelenmesi planlandı.

\section{Gereç ve Yöntemler}

Çalışmamızda hastanemiz çocuk endokrinoloji kliniğinde Ocak 2015-Ocak 2019 tarihleri arasında yatırılarak izlenmiş DM tanılı (E10-14diyabetes mellitus ICD kodları tarandı) hastaların dosya verileri geriye dönük olarak incelendi. Diyabet tanı ve sınıflaması International Society for Pediatricand Adolescent Diabetes (ISPAD) önerilerine göre yapıldı (1). Hastalar yeni tanı alanlar ve eski tanılı hastalar olarak gruplandırıldı. Yeni tanı alan hastaların başvurudaki metabolik durumları laboratuvar verilerine göre hiperglisemi (açlık glukoz>126 mg veya tokluk glukoz düzeyi > $200 \mathrm{mg} / \mathrm{dl}$ olup ketozis (ketonemi ve ketonüri) ve/veya asidozu olmayan hastalar), ketozis (hiperglisemi ile birlikte ketozisi olup asidozu olmayan hastalar) ve diyabetik ketoasidoz (hiperglisemi ve ketozis ile birlikte metabolik 
asidozu (venöz $\mathrm{pH}<7,3, \mathrm{HCO} 3<15 \mathrm{mmol} / \mathrm{L}$ ve ketonemi/ ketonüri saptanması) olmak üzere 3 gruba ayrıldı. Ketoasidoz venöz pH'ya göre 3 gruba ayrıldı ( $\mathrm{pH} 7,3-7,2$ hafif; 7,2-7,1 orta; $<7,1$ ciddiketoasidoz). Eski tanılı hastaların ise tekrar yatış nedeni, eğitim tekrarı ve regülasyon, ketoz/ketoasidoz gelişmesi, rejim değişikliği, insulin pompası takılması, girişimsel işlem, hipoglisemik konvulzyon, kan basıncı monitorizasyonu, glukoz profilinin değerlendirilmesi ve diğer nedenler olarak gruplandırıldı. Aynı hastanın tekrarlayan hasteneye yatışlarının her biri ayrı veri olarak değerlendirildi. $\mathrm{Bu}$ çalışma için hastanemiz etik kurulundan onam alındı (No: 2020/10-018). Geriye dönük çalışma olması nedeniyle hastalardan yazılı onam alınmadı.

İstatistiksel analizler için SPSS versiyon 24.0 (SPSS Inc. Chicago, IL, USA) programı kullanıldı. Kategorik veriler frekans (yüzde) ile ifade edilirken, sayısal veriler ortalama \pm standart sapma(minimum- maksimum) olarak ifade edildi. Kategorik verileri karşılaştırmak amacıyla Ki-kare testleri kullanıldı.
$\mathrm{P}<0,05$ olan değerler istatistiksel olarak anlamlı kabul edildi.

\section{Bulgular}

Dört yılda 554 DM tanılı hastaya ait 787 yatış belirlendi. Yatışı yapılan hastaların \%52,1'i kız, yaş ortalaması 10,9 \pm 4,6 yıl (0,122,0 ) olup, ortalama hastanede kalış süresi 10,1 $\pm 5,5$ gün olarak saptandı. Toplam yatışların 382'si (\%48), bu süreçte hastaneye en az 2 defa yatışı gereken 149 hastaya (toplam hasta sayısının $\left.\% 26,8^{\prime} i\right)$ ait mükerrer yatıştı. Yatışların 277 'si $(\% 35,1)$ yeni tanı almış, 510’u (\%64,9) daha önceden DM tanısı almış hastalara aitti. Yatışların yıllara göre dağılım yüzdesi sırayla \%19,0, \%21,6, \%29,7 ve \%29,6 olup son iki yılda DM tanılı hastalara ait yatış sayısında artış gözlendi $(p=0,016)$. Yatışı yapılan hastaların diyabet tiplerine göre dağılımı, 713 hastada $(\% 90,6)$ T1DM, 33 hastada $(\% 4,2)$ T2DM, 19 hastada(\%2,4) Maturity Onset Diyabet Of Young (MODY), 9 hastada $(\% 1,1)$ yenidoğan diyabeti, 8 hastada $(\% 1,0)$ Wolfram Sendromu ve 5 hastada $(\% 0,6)$ diğer olarak belirlendi. Diyabet tiplerinin yıllara göre dağılımı Tablo1'de verilmiştir.

\begin{tabular}{|c|c|c|c|c|c|c|c|}
\hline & $\begin{array}{l}\text { T1DM } \\
\text { n(\%) }\end{array}$ & $\begin{array}{c}\text { T2DM } \\
\text { n(\%) }\end{array}$ & $\begin{array}{c}\text { MODY } \\
\mathrm{n}(\%)\end{array}$ & $\begin{array}{c}\text { YD } \\
\text { n(\%) }\end{array}$ & $\begin{array}{c}\text { WS } \\
n(\%)\end{array}$ & $\begin{array}{l}\text { Diğer } \\
\text { n(\%) }\end{array}$ & $\begin{array}{c}\text { Toplam } \\
\mathrm{n}(\%)\end{array}$ \\
\hline 2015 & $137(19,2)$ & $5(15,2)$ & $2(10,5)$ & $0(0)$ & $4(50)$ & $2(40)$ & $150(19,1)$ \\
\hline 2016 & $147(20,6)$ & $8(24,2)$ & $8(42,1)$ & $3(33,3)$ & $2(25)$ & $2(40)$ & $170(21,6)$ \\
\hline 2017 & $216(30,3)$ & $8(24,2)$ & $4(21,1)$ & $4(44,4)$ & $2(25)$ & $0(0)$ & $234(29,7)$ \\
\hline 2018 & $213(29,9)$ & $12(36,4)$ & $5(26,3)$ & $2(22,2)$ & $0(25)$ & $1(40)$ & $233(29,6)$ \\
\hline Toplam & $713(100)$ & $33(100)$ & $19(100)$ & $9(100)$ & $8(100)$ & $5(100)$ & $787(100)$ \\
\hline
\end{tabular}

T1DM hastalarının 239'unun yeni tanı aldığı(yeni tanı alan DM hastalarının \%86,3'ü) ve yeni tanı T1DM hasta sayısının son 2 yılda daha fazla olduğu gözlendi (2015'ten itibaren yıllara göre sırayla 50, 45, 78 ve 66 hasta, $p=0,005)$. Yeni tanı T1DM hastalarının \%47,7'si kız, yaş ortalaması 8,9 $44,4(1,1-17,9)$ yıl olup yaş dağılımı Şekil 1'de verilmiştir.Cinsiyet dağılımında yaşa göre farklılık gözlenmedi (10 yaş altında \%51 kız, \%49 erkek; 10 yaş üstünde \%42 kı, \%48 erkek).Yenitanı T1DM hastalarının, \%27,7'sininhiperglisemi, \%22,6'sınınketozis, ve $\% 49,7$ 'sininketoasidoz (hafif $\% 28,5$, orta $\% 27,7$, ağır \%43,7) ile tanı aldığı ve 5 yaşından küçük hastalarda başvuruda ketoasidoz oranının 5 yaşından büyük hastalara göre daha yüksek olduğu (<5 yaş $\% 69,2(n=36 / 52), 5-10$ yaş $\% 41,3$ $(n=38 / 92),>10$ yaş \%47,3 $(n=44 / 95))$ belirlendi $(p<0,001)$. Başvuruda metabolik durumun yıllara göre dağılımı incelendiğinde ketoasidozla başvuru oranında yıllar içinde belirgin azalma gözlendi ( $p=0,03)$ (Şekil 2).

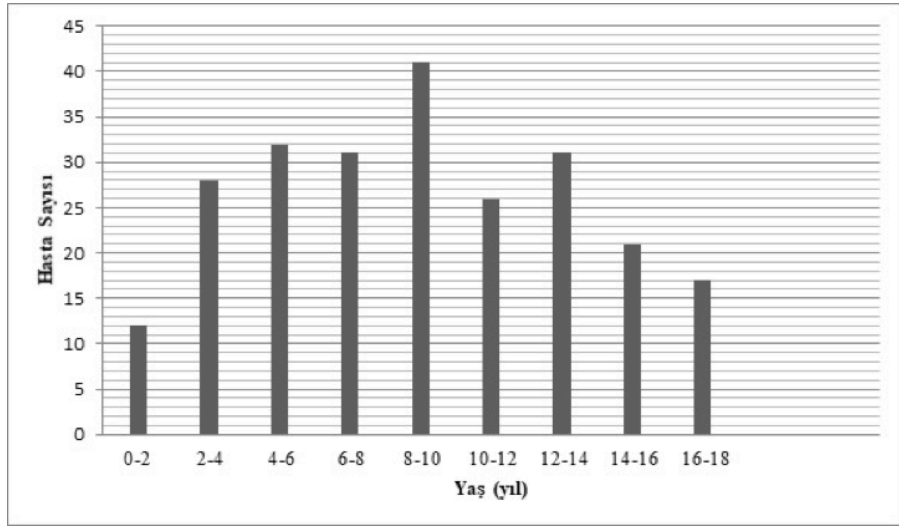

Şekil 1. Servise yeni tanı tip 1 diyabetes mellitus tanısı ile yatırılan olguların yaş dağılımları (2015-2019 yılları arası) 


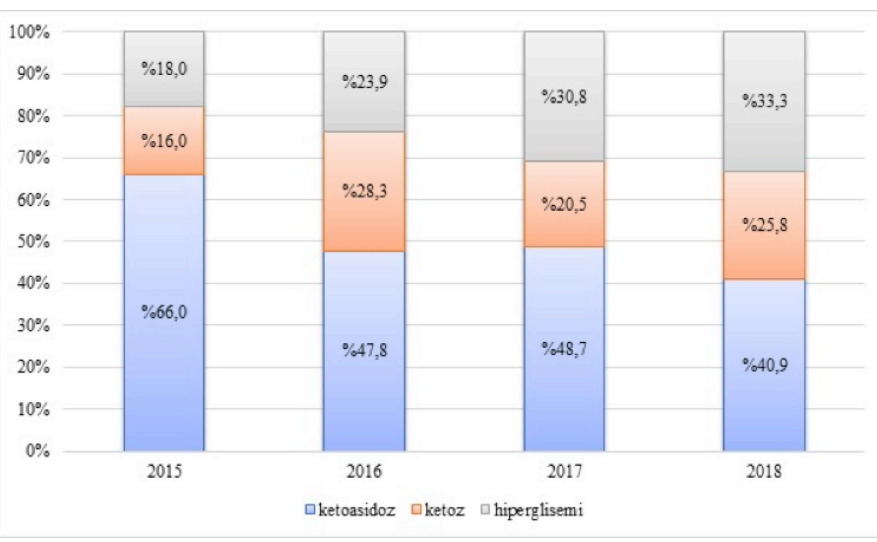

Şekil 2. Servise yeni tanı tip 1 diyabetes mellitus tanısı ile yatırılan olguların başvuru şekilleri (2015-2019 yıllari arası)

T2DM hastalarının 20'si yeni tanı almıştı (yeni tanı alan DM hastalarının \%7,2'si, yıllara göre oranı sırasıyla \%5,4, \%8,6, $\% 6,8, \% 7,9)$. Yeni tanı alan T2DM hastalarının yaş ortalaması 13,07 $\pm 2,6$ yıl (8,3-17,5), \%75'i kız, ortalama vücut kitle indeksi

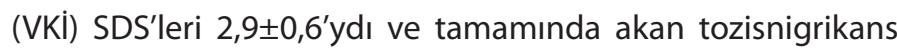
olduğu saptandı. Olguların \%61'inin anne ve/veya babasında da diyabet öyküsü mevcuttu. Yeni tanı alan T2DM hastalarının \%25'inin oral glukoz tolerans testi (OGTT) ile, \%75'inin hiperglisemi ile tanı aldığı belirlendi. Tanı anındaki ortalama HbA1C düzeyi \%8,3 22,8 bulundu. Yeni tanı T2DM hasta sayısının yıllara göre dağılımı 2015'ten itibaren yıllara göre sırayla 3,5 ve 6'şar hasta olarak belirlendi.

MODY'nin klinik ve laboratuar kriterlerini taşıyan 19 hastanın 11'i yeni tanı almıştı (yeni tanı alan DM'lerin \%4'ü). MODY

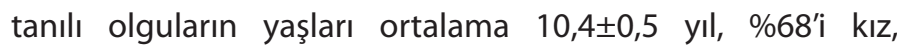
HbA1C ortalaması $\% 6,02 \pm 0,2^{\prime} y d i$. Olguların tamamı sadece hiperglisemi ile tanı almıştı. Olguların \%74'ünün genetik mutasyonu gösterilebildi (8 hastada GCK, 3 hastada HNF1A, 1 hastada HNF4A, 1 hastada GLIS 3 ve 1 hastada KCNJ11 heterozigot mutasyonu). 3 olgunun genetik tetkikleri ailesel nedenlerle sonuçlandırılamazken 2 olgunun genetik çalışmasında mutasyon saptanmadı. Wolfram sendromlu 4 olguya ait 8 yatış değerlendirildi. Olguların hepsi DM tanısını takiben optik atrofi ve diyabetes inspidus tespit edilmesiyle önceden Wolfram sendromu tanısı almıştı. Olgulara ait hastaneye yatışların 5'i regülasyon/eğitim tekrarı, 3'ü desmopressin doz ayarlanması amacıyla yapılmıştı.

Daha önce DM tanısı olup yatışı gereken hastalara ait yatış sayısının son 2 yılda daha fazla olduğu (2015'ten itibaren yıllara göre sırayla 95, 112, 147 ve 156 yatış, $p=0,001$ ), yatış nedenleri incelendiğinde \%72,4'ünün regülasyon ve eğitim tekrarı için hastaneye yatırıldığı belirlendi. Bu yatışların \%94,8'i T1DM tanılı hastalara aitti, HbA1C ortalamaları \%9,2 $\pm 2,4$ 'tü, yaş ortalamaları $11,8 \pm 4,3(0,2-22)$ yıldı ve \%51,5'i 10-16 yaş aralığındaydı (Şekil 3). Önceden diyabet tanısı olan hastaların $\% 6,3$ 'ünün ise ketoz/ketoasidoz (ketosis $n=5$, ketoasidoz $n=27$ ) gelişmesi nedeniyle hastaneye yatırıldığı ve bu hastaların tamamının T1DM'li olduğu belirlendi. Ketoz/ketoasidoz nedeniyle yatırılan eski tanılı hastaların yaş ortalaması $12,4 \pm 2,9(3,5-16,4)$ yıldı, \%90,6'sı 10-16 yaş aralığındaydı ve tamamı T1DM tanılıydı. Diyabet tanısı ile takip edilmekte olan hastaların hastaneye yatış nedenleri Şekil 4'de verilmiştir.

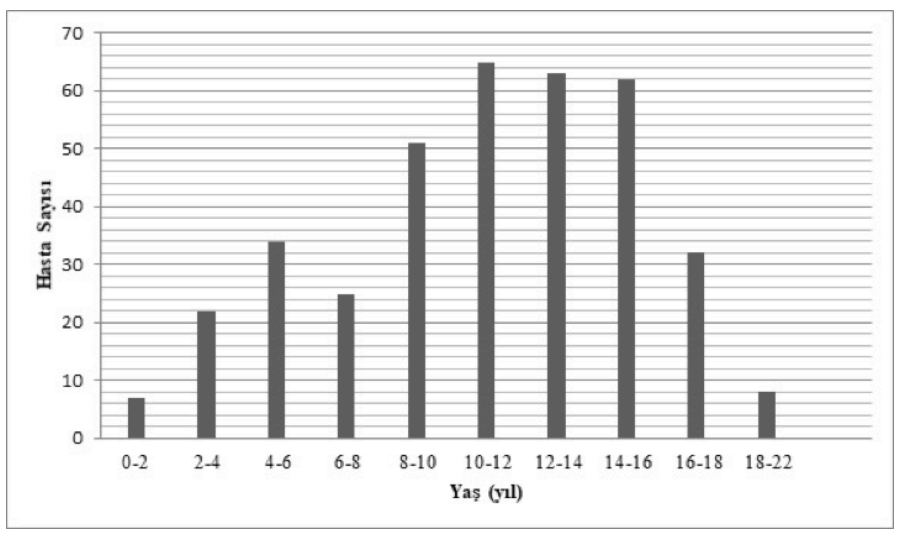

Şekil 3. Servise eski tanı tip 1 diyabetes mellitus tanısı ile yatırılan olguların yaş dağılımları (2015-2019 yılları arası)

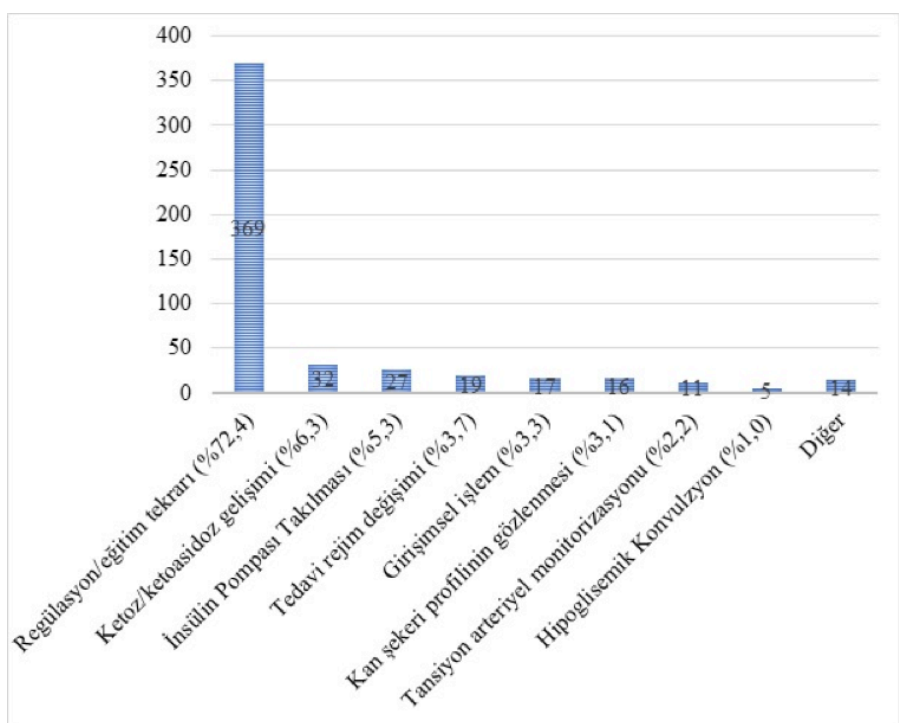

Şekil 4. Servise yatırılan diyabetes mellitus tanılı olguların yatış nedenleri (2015-2019 yılları arası)

\section{Tartışma}

Bu çalışmada, tüm dünyada ve yaş gruplarında artan diyabet insidans ve prevalansıyla uyumlu olarak, son iki yılda diyabete 
bağlı hastaneye yatış oranlarında artış olduğu saptandı [5]. Son yıllarda bazı yazarlar ketoasidoz veya ketonürisi olmayan DM tanılı hastalara ilk tedavi ve eğitimin ayaktan verilebileceğini belirtse de hastanemizde tüm yeni tanı DM hastaları tedavi düzenlemesi ve diyabet eğitimi için yatırılmaktadır [6]. Bu nedenle, çalışmaya dahil edilmiş yeni tanı DM tanılı hastalar hastanemizde son 4 yılda tanı almış tüm DM tanılı hastaları kapsamaktaydı ve yeni tanı diyabet hastaları içinde T1DM sıklığı literatürle uyumlu olarak \%86,3 bulundu [7].

Diyabetik ketoasidoz ve komplikasyonları T1DM'de en önemli hastaneye yatış, morbidite ve mortalite nedenidir.Küçük çocuklarda tek bir ketoasidoz atağı bile düşük IQ skorları, daha zayıf bilişsel performans ve beyin gelişiminde azalma ile ilişkili bulunmuştur. Diyabette ketoasidozla başvuru oranı bölgesel düşük T1DM insidansı, küçük yaş, düşük sosyoekonomik düzey gibi faktörlerle ilişkilidir [8]. Tanı anında ketoasidozu olan T1DM hastalarının oranı Kuzey Amerika'da \%25-30'ken, dünya genelinde \%58'e ulaşan oranlar bildirilmiştir [9-11] . Ülkemizde son 10 yılda yayınlanmış çalışmalarda kümülatif ketoasidoz oranları \%24-43 arasında olup hastanemizin verileri yıllar içerisinde azalma gösterse de hem ülke hem de dünya ortalamasının üzerinde yer almaktadır [12-14]. Bu tablonun, hastanemizin hizmet verdiği bölgenin sosyoekonomik seviyesi ve çevre illerden sevk kabul oranının yüksek olmasıyla ilişkili olduğu düşünüldü. Ülkemizde yürütülmüş bir çalışmada da, eğitim ve araştırma hastanelerinde diyabetik ketoasidoz oranı üniversite hastanelerine göre daha yüksek bulunmuş (\%77 vs \%23) ve bu durum sevk zinciri, ulaşım ve hastanelerdeki yer durumuyla ilişkili bulunmuştur(13). Çalışmamızda yıllar içinde ketoasidoz oranının düşmesinin Çocuk Endokrinolojisi ve Diyabet Derneğinin Okulda Diyabet Programı (www.okulda diyabet.com) kapsamında farkındalık konusundaki faaliyetleri ile ilişkili olabileceği kanaatindeyiz [15]. Ancak, özellikle son 10 yılda hem ülkemizin farklı bölgelerinde hem de dünyada, ulusal diyabet farkındalık programlarına karşın değişmeyen/ artan ketoasidoz oranları bildirilmektedir [10-14].

T2DM hastalarının tümyenitanı diyabetlerin \%7'sini oluşturduğu gözlendi. Obezitenin artmasıyla birlikte tüm dünyada hemT2DM sıklığı artmış hem de daha erken yaşta görülmeye başlanmıştır [3]. Çocukluk çağı diyabetleri arasında T2DM oranı son 30 yılda \%3'ten \%20'ye yükselmiştir ve adelosan yaş grubunda bazı etnik gruplarda \%50'yi aşan oranlar bildirilmektedir [16]. Ülkemizde yapılmış bir çalışmada da T2DM'nin 18yaşaltı DM tanılı hastaların \%17'sini oluşturduğu gözlemlenmiştir [12]. T2DM'de ortalama tanı alma yaşı ergenliğe bağlı insülin direncinin pik yaptığı 13,5 yaş olarak bildirilmektedir [17]. Obezite, kız cinsiyet ve ailede diyabet öyküsü T2DM gelişimi için risk faktörleri arasındadır. Çalışmamızda da literatürü destekler şekilde T2DM tanısı alan hastaların ortalama yaşı 13 yaş, VKi yüksek, büyük çoğunluğu kız cinsiyetteydi ve \%60'ının en az bir ebeveyni T2DM tanılıydı. Çocukluk çağı T2DM’nda hastaların yaklaşık \%40'ı başvuruda asemptomatik, \%57-70'i ketozis olmadan hiperglisemiktir [1819]. Ketoasidozla başvuru ise $\% 5$ gibi düşük oranlarda gözlenir. Çalışmamızda ketoasidozla tanı alan T2DM hastası yoktu ancak hastaların \%75'i semptomatikti ve hiperglisemi ile tanı almıştı.

Ergenlik veya erken yetişkinlik döneminde ortaya çıkan ailevi, hafif, ketotik olmayan diyabet olarak tanımlanan MODY artık beta hücrelerinin gelişimi veya işlevi için önemli genlerdeki heterojen mutasyonlar nedeniyle gelişen 'monogenik diyabet' başlığı altında incelenmektedir[1]. Ancak ailede 2 kuşakta genç başlangıçlı diyabet öyküsü, ölçülebilir c peptit düzeyleri ve insülin direnci bulgularının yokluğuna karşın hastaların bir kısmında genetik mutasyon gösterilemeyebilir. Toplumlara göre sıklığı değişmekle birlikte MODY'de en sık görülen mutasyonlar HNF1A (\%52-65) ve GCK (\%15-32) genlerindedir [20,21]. Çalışmamızda genetik araştırması tamamlanmış MODY hastalarında en sık görülen mutasyon GCK, ikinci sıklıkta ise HNF1A genindeydi. Ülkemizden yayınlanmış pek çok diğer çalışmada da GCK gen mutasyonları MODY'nin en sık nedeni olarak belirtilmektedir [12]. Wolfram sendromu erken başlangıçlı DM, diyabetes insipidus, optikatrofi, işitme kaybı ve nörodejenarasyon ile karakterize nadir bir genetik hastalıktır. Çocukluk çağı diyabet olgularının 1/150'sini oluşturur [22]. Nörolojik disfonksiyona bağlı ciddi hipoglisemi atakları T1DM'ye göre daha sık gözlenir. Diyabetes mellitus komplikasyonları, diyabetes insipidus/desmopressin tedavisine bağlı elektrolit bozuklukları, nörojenik mesaneye bağlı komplikasyonlar ve nöropsikolojik bozukluklar nedeniyle Wolfram Sendromlu olgularda yakın takip önemlidir ve tanı sonrası tekrarlanan hospitalizasyonlar gerekebilir[23].

Diyabetes Mellitus tanılı hastaların sadece tanı anında değil, takipleri boyunca hastaneye tekrarlayan yatışları gerekebilir. Bu konuda yapılmış çok az çalışma mevcut olup, ulaşabildiğimiz en kapsamlı araştırmada Almanya'dadiyabetes mellitus tanılı çocuk ve adelosanların yatışları ICD kodu üzerinden 
belirlenmiş, yeni/eski tanı olarak ayrı değerlendirilmemiştir. Çalışmada 7 yıllık zaman diliminde hastaneye yatışı yapılmış 4746 DM tanılı olgunun \%11,8'inin bu süreçte tekrarlayan yatışı olduğu belirtilmiş ancak ketoasidozla tekrar başvuru oranı belirtilmemiştir [24]. Çalışmamızda tekrarlayan yatışı olan olguların oranı \%26,8'di. İki yıllık yatışı yapılmış DM tanılı hastaların verilerinin incelendiği Almanya'dan yapılmış bir başka çalışmada eski/yeni tanı ayrımı yapılmadan ketoasidoz oranı \%18 olarak bildirilmiştir [4]. 30 yıllık klinik tecrübemiz ile diyabetin kronik bir hastalık olması ve ailelerin ve hastaların sık sık diyabet takip önerilerini uygulama konusunda tükenmişlik yaşadıklarını görmekteyiz. Klinik bilgilerimiz ve gözlemlerimiz; rutin kontroller sırasında kayıt tutmayan, beslenmesine uymayan, ebeveynlerin tüm kontrolü çocuklara ve adolesanlara bıraktığı durumlarda; hekim, diyabet eğitim hemşiresi, psikolog ve gerekli durumlarda sosyal hizmet uzmanı ile soruna yönelik yaklaşımlar yapılmakta, bu yaklaşım sonrası ayaktan kan şekeri ölçümleri ve insülin dozu takibi, motivasyonlarının arttırılması, evde kötü takip sürecine girmiş olumsuz sürecin tekrar olumlu sürece evrilmesi hedeflenmekte, kontrole çağrılan hastalarda durumda değişiklik olmamışsa yatış yapılarak; eğitim tekrarı, psikolojik ve sosyal destek sağlanmaktadır. Bu yaklaşımın diyabet izleminde son derece önemli bir yaklaşım olduğu kanaatindeyiz. Eski tanı DM'li hastalarda en sık yatışın adolesan yaş grubunda olmasının da adolesan yaşlarda diyabet izlemi konusundaki özenin literatür ile uyumlu şekilde daha sık bozulmasına bağlamaktayız [25]. Bu dönemde kronik hastalıkla başetme becerilerinin geliştirilmesi için tekrarlı yatışlar yapılması gerekebileceği göz önünde bulundurulmalı ve diyabet eğitiminin sürekliliği sağlanmalıdır.

\section{Sonuç}

Tüm dünyada hem T1DM hem de T2DM görülme sıklığı artmaktadır. T1DM'de ketoasidozla başvuru oranlarının azalması için diyabet farkındalığını arttırmaya yönelik programlara ağırlık verilmeli, T2DM sıklığını azaltmaya yönelik toplum obezite konusunda bilinçlendirilmelidir.

\section{Çıkar çatışması/finansal destek beyanı}

Çalışmayı maddi olarak destekleyen kişi/kuruluş yoktur ve yazarların herhangi bir çıkar dayalı ilişkisi yoktur.

\section{Kaynaklar}

1. Mayer-Davis EJ, Kahkoska AR, Jefferies C, et al. ISPAD Clinical Practice Consensus Guidelines 2018: Definition, epidemiology, and classification of diabetes in children and adolescents. Pediatr Diabetes 2018; 27: 7-19.

2. Cho N, Shaw J, Karuranga S, et al. IDF Diabetes Atlas: Global estimates of diabetes prevalence for 2017 and projections for 2045. Diabetes research and clinical practice2018;138:271-81.

3. Pulgaron ER, Delamater AM. Obesity and type 2 diabetes in children: epidemiology and treatment. Curr Diab Rep 2014; 14: 508.

4. Bohn B, Schwandt A, Ihle $P$, et al. Hospital admission in children and adolescents with or without type 1 diabetes from Germany: An analysis of statutory health insurance data on 12 million subjects. Pediatr Diabetes 2018; 19: 721-6.

5. Mobasseri M, Shirmohammadi M, Amiri T, Vahed N, Hosseini Fard $H$, Ghojazadeh M. Prevalence and incidence of type 1 diabetes in the world: a systematic review and meta-analysis. Health Promot Perspect 2020; 10: 98-115.

6. Jasinski $\mathrm{CF}$, Rodriguez-Monguio $\mathrm{R}$, Tonyushkina $\mathrm{K}$, Allen $\mathrm{H}$. Healthcare cost of type 1 diabetes mellitus in new-onset children in a hospital compared to an outpatient setting. BMC Pediatr 2013; 13: 55

7. Liese $A D$, D'Agostino RB, Jr., Hamman RF, et al. The burden of diabetes mellitus among US youth: prevalence estimates from the SEARCH for Diabetes in Youth Study. Pediatrics 2006; 118: 1510-8.

8. Wolfsdorf J, Glaser N, Sperling MA. Diabetic ketoacidosis in infants, children, and adolescents: A consensus statement from the American Diabetes Association. Diabetes Care2006; 29: 1150-9.

9. Dabelea D, Rewers A, Stafford JM, et al. Trends in the prevalence of ketoacidosis at diabetes diagnosis: the SEARCH for diabetes in youth study. Pediatrics2014; 133: 938-45.

10. Rabbone I, Maltoni G, Tinti D, et al. Diabetic ketoacidosis at the onset of disease during a national awareness campaign: a 2-year observational study in children aged 0-18 years. Arch Dis Child 2020; 105: 363-6.

11. Souza L, Kraemer GC, Koliski A, et al. DIABETIC KETOACIDOSIS AS THE INITIAL PRESENTATION OF TYPE 1 DIABETES IN CHILDREN AND ADOLESCENTS: EPIDEMIOLOGICAL STUDY IN SOUTHERN BRAZIL. Rev Paul Pediatr 2020; 38: 2018204. 
12. İşleyen F, Semih B. Adıyaman İlindeki Diyabetik Çocukların Epidemiyolojik Özellikleri. Güncel Pediatri2019;17:1-16.

13. Demir K, Büyükinan M, Dizdarer C, et al.Tip 1 diyabetli çocuklarda tanıda diyabetik ketoasidoz sıklığı ve ilişkili faktörler. Güncel Pediatr i2010; 8: 52-5.

14. Acar S, Gören Y, Paketçi A, et al. Tip I Diabetes Mellitus Olgularinin Tani Anindaki Diyabetik Ketoasidoz Sikliginin Degisimi: On Bes YillikTek Merkez Deneyimi/Changes in the Frequency of Diabetic Ketoacidosis in Type I Diabetes Mellitus Cases at Diagnosis: A Fifteen-Year Single Center Experience. The Journal of Pediatric Research 2017; 4: 143-9.

15. Hatun Ş. Diabetes program at schools in Turkey. J Clin Res Pediatr Endocrinol2012;4:114-5.

16. Dabelea D, Bell RA, D'Agostino RB, Jr., et al. Incidence of diabetes in youth in the United States. Jama 2007; 297: 2716-24.

17. Rosenbloom $A L$, Silverstein $J H$, Amemiya $S$, Zeitler $P$, Klingensmith GJ. ISPAD Clinical Practice Consensus Guidelines 2006-2007. Type 2 diabetes mellitus in the child and adolescent. Pediatr Diabetes 2008; 9: 512-26.

18. Mayer-Davis EJ, Beyer J, Bell RA, et al. Diabetes in African American youth: prevalence, incidence, and clinical characteristics: the SEARCH for Diabetes in Youth Study. Diabetes Care2009; 32: 112-22.
19. Jefferies C, Carter P, Reed PW, et al. The incidence, clinical features, and treatment of type 2 diabetes in children $<15 \mathrm{yr}$ in a population-based cohort from Auckland, New Zealand, 19952007. Pediatr Diabetes 2012; 13: 294-300.

20. Fajans SS, Bell Gl, Polonsky KS. Molecular mechanisms and clinical pathophysiology of maturity-onset diabetes of the young. N Engl J Med 2001; 345: 971-80.

21. Shields BM, Hicks S, Shepherd MH, Colclough K, Hattersley AT, Ellard S. Maturity-onset diabetes of the young (MODY): how many cases are we missing? Diabetologia 2010; 53: 2504-8.

22. Ganie MA, Bhat D. Current developments in Wolfram syndrome. J Pediatr Endocrinol Metab 2009; 22: 3-10.

23. Pallotta MT, Tascini G, Crispoldi R, et al. Wolfram syndrome, a rare neurodegenerative disease: from pathogenesis to future treatment perspectives. J Transl Med 2019; 17:238.

24. Auzanneau M, Bohn B, Schiel R, et al. Inpatient Rehabilitation for Children and Adolescents With Diabetes in Germany Between 2006 and 2013. Exp Clin Endocrinol Diabetes 2020; 128: 325-31.

25. Rewers A, Chase HP,MackenzieT, et al. Predictors of acute complications in children with type 1 diabetes. Jama2002; 287:2511-8. 